\title{
Factors Affecting UAE Consumers' Attitudes Towards Using Social Networking Sites in Hotel Selection
}

\author{
Dr. Hamza Salim Khraim \\ Faculty of Business, Department of Marketing, Amman Arab University, Amman - Jordan
}

\begin{abstract}
This study focuses on the influence of social networking sites on travelers' attitudes towards hotel selection in the UAE. A social networking site (SNS) is a form of social media that provides a platform for people to connect with each other. It is very important to examine how individual travelers are utilizing SNS when they select a hotel. Therefore, the objective of this study is to investigate if Perceived Ease of Use (PEU), Perceived Usefulness (PU), and Perceived Risk (PR) have any influence on attitude toward using social media (ATUSM). The study will use an exploratory research design which employs quantitative data. Convenience sampling technique was used to distribute the self-administered survey questionnaires on different hotels in the UAE. As hypothesized, the results show the positive effect of Perceived Ease of Use (PEU), Perceived Usefulness (PU), and Perceived Risk (PR) on consumers' attitude toward using social media (ATUSM) in hotel selection.
\end{abstract}

Keywords: social networking sites, attitude, perceived ease of use, perceived usefulness, perceived risk, hotel selection

DOI: $10.7176 / \mathrm{JMCR} / 66-03$

Publication date:March $31^{\text {st }} 2020$

\section{Introduction:}

Remarkable software technology development and advancement in internet services have led to an increase in the number of users and their ability to be connected on the internet with friends and family in different countries. After the advent of Web 2.0, Social Networking Sites (SNS) offer direct social networking, which has enabled it to become a global phenomenon. Riley (2010) illustrates that it is much easier to get and stay connected through SNS such as Facebook, Twitter, Instagram, etc. One of the unique advantages of Web 2.0 is that it allows the exchange of user-generated content. Web 2.0 is a platform which is characterized by the continuous modification of content and applications, and permits exchanges by all users in a participatory and collaborative manner (Kaplan \& Haenle, 2010). In the early stages of Web 2.0, consumers used SNS for entertainment, but soon after the substantial development in information communication technologies, consumers start using SNS to communicate with each other. Convenience is another key benefit associated with SNS because they allow ease of access to customer replies. Global-free interaction between users is another advantage that consumers can benefit highly from the Facebook. Those free services include upload photos, share posts, chat, comment on the posts, and also get replies from other consumers who share the same interests. For companies, this advantage can provide them with instant feedback and allow them to send a direct response to customers. As of January 2019, there were 3.397 billion active social media users. Social media users grew by 320 million between September 2017 and October 2018 (brandwatch.com, 2019). The numbers of social media users are presented in Table 1.

Table1. Social Media Statistics

\begin{tabular}{|c|c|}
\hline SNS & Number of users \\
\hline Facebook & 2.271 billion \\
\hline YouTube & 1.5 billion \\
\hline Instagram & 1 billion \\
\hline LinkedIn & 562 million \\
\hline Reddit & 542 million \\
\hline Twitter & 326 million \\
\hline Source: brandwatch.com (2019) \\
\hline
\end{tabular}

In comparison with many other social media platforms such as Instagram and Twitter, Facebook is most widely used for hotels' online communities as it has 2 billion monthly active users worldwide (Statista, 2017). Quach (2017) maintained that winning hotels need to adopt the new communication methods used by consumers, and to be able to use up-to-date social media marketing trends to cope with changes in consumer behavior and expectations by developing a dynamic online presence. This was confirmed by (Luo \& Zhong, 2015; Kim \& Park, 2017)) who indicated that hotel industry has increasingly adopted social media, particularly in the form of SNS, and playing a key roles in advertising, marketing and promotions within the hotel industry.

Garrido-Moreno \& Lockett (2016) asserted that the adoption and use of SM tools by hoteliers help them to better approach their customers, improve their image, and give them a touch of modernity. There are many consumers who see social networking sites as the most trusted source of information due to information being 
provided by people they know, or at least have a passing acquaintance with (Fotis, Buhalis \& Rossides, 2012). Garrido-Moreno \& Lockett (2016) found that review sites and social networking were the most-used SM tools with regard to European hotels. This increasing adoption of social media has changed methods of interaction and participation in the hotel industry (Leung \& Baloglu, 2015). Among many different internet-based applications in hotels, SNS in particular are currently flourishing (Kim \& Chae, 2018). Based on this, businesses have come to realize that social media is a critical factor in the world of business.

The tourism industry in the UAE is currently using SNS to attract visitors (Kargwell, 2016; Sigala, Gretzel $\&$ Christou, 2012). Therefore, it is important to determine how individual travelers are utilizing SNS when they select a hotel. Thus, the research problem arises as hotels have to be aware of the different factors that influence individual traveler's use of SNS in hotel selection. Despite this importance, no empirical study has gauged the attitude with regard to using social media in the context of hotel selection in the UAE to date. Such influence remains unclear and requires further investigation. This paper aims mainly to explore the factors that affect customers' attitudes towards using SNS in hotel selection. More specifically, this study will try to explore the influence of Perceived Ease of Use (PEU), Perceived Usefulness (PU), and Perceived Risk (PR) on attitude toward using social media (ATUSM) in hotel selection. In terms of the structure of this research, section 2 will present the literature review, section 3 will describe the methodology of the study, section 4 will discuss the results, and section 5 will offer a discussion and conclusions. Finally, section 6 will address the limitations of the research.

\section{Literature Review \\ 2.1 Social Media}

Social media is one of the most commonly-used channels for helping customers to search for their ideal choice of hotel. Social media covers a broad range of internet applications, including online review sites (e.g. TripAdvisor), social networking sites (SNS) (e.g. Facebook and Twitter) and content sharing platforms (e.g. YouTube) (Kaplan \& Haenlein, 2010). One fascinating aspect of social media is their potential to move markets by driving consumers' purchasing patterns and influencing lodging performance (Anderson, 2012; Sigala, Gretzel \& Christou, 2012). Social media has created an online culture that encourages users to share experiences, and has changed the way we think and behave. Social media such as Facebook and Instagram attracts users because they allow them to spend time refining and editing their image, resulting in users spending more time doing this then engaging with people around them. Varkaris \& Neuhofer (2017) affirmed that social media play a key role in tourism and hospitality, transforming the way tourists search, find and co-create information about travel-related products, and change the way they make hotel-related decisions. Overall, social media have been portrayed as significant platforms for information exchange, and for interaction between businesses and consumers and among users, including wider mediators, controllers, and non-profit organizational stakeholders (Sigala, Gretzel \& Christou, 2012).

\subsection{Social Networking Sites (SNS)}

Back to 1997, SixDegrees.com was launched as the first social networking site. The site provided various services to users such as creating profile and to surf the friends' lists. The main idea that SixDegrees tried to bestow was to connect people by sending and receiving messages. This feature attracts millions of customers, but it failed to become a sustainable business and, in 2000, the service closed (Boyd \& Ellison, 2008). From 2003 onwards, many new SNS were launched, with most taking the form of profile-centric sites. While SNS have implemented a wide variety of technical features, their backbone consists of visible profiles that display an articulated list of friends who are also users of the system. SNS vary greatly in their features and user base. Some have photo-sharing or video-sharing capabilities, while others have built-in blogging and instant messaging technology. Madni (2014) pointed out that SNS such as Facebook and MySpace generally have some common features such as 1) users being capable of to joining interacting accounts, 2) users being capable of creating a catalog of recommended friends, and 3) users being capable of navigating their list of recommended friends and those provided by other users in the system. Boyd \& Ellison (2007) defined Social Media Networking (SMN) as a web-based application that allows anyone to construct any web content, ranging from photos and videos to descriptions such as personal, organizational, or employer details. In addition, Trusov, Bucklin \& Pauwels (2009) have described SNS as networks of friends for social or professional interaction. Finally, Shen, Chengyi, Mimi \& Jiang (2015) defined SNS as internet platforms that help people build their own social networks online, and which are centered on user experience and the expansion of social connections.

\subsection{Social Media Users in the UAE}

As we mention earlier that UAE is the fastest-growing country in terms of technology, which make it possible for $99.26 \%$ of the UAE population to use different types of social media. In 2018, 9.38 million people out of 9.45 million people come online on social media on a daily basis. This can be attributed to the high growth in mobile social users, which reach $6 \%$ in 2018 . At the same year, statistics show that the number of mobile 
social media users in the country recorded a $6 \%$ growth with more than 500,000 new users. Facebook is considered as the most attractive social media platform in UAE, but statistics also show that it is closely followed by the fast-growing YouTube community. Almost $83 \%$ of the UAE's population has profiles on Facebook, while YouTube's penetration stands at 79\%. Facebook has found favor among the commercial entities, political classes as well as the general population of the country.

Table2. Popular Social Networks in the UAE

\begin{tabular}{|l|c|}
\hline Social Network Platforms & Active Users \\
\hline Facebook & 7.82 million \\
\hline YouTube & 7.54 million \\
\hline Instagram & 5.06 million \\
\hline Twitter & 3.91 million \\
\hline LinkedIn & 3.82 million \\
\hline Google+ & 3.63 million \\
\hline Pinterest & 2.10 million \\
\hline Source: UAE Social Media Usage Statistics (2018) \\
\hline
\end{tabular}

\subsection{Attitude towards using social media (ATUSM) in terms of hotel selection}

Kang \& Kim (2006) demonstrate that when consumers use social networking services, they develop an attitude towards the service which, results in them making a positive or negative judgment. This fact has encouraged hotels to create their own websites and made use of hotel booking websites that advertise the hotel based on the information offered by the hotel itself (Jung, Gyehee, Hur, Taegoo \& Kim 2018). One of the most valuable advantages of social media is the flexibility in communication techniques such as showing pictures of rooms, pools, reception, and the surroundings that they think would attract customers from all over the world. Hotel websites have different information based on their marketing strategy, for example some hotels show price lists and offer deals that can differ from those featured by agencies or by hotel booking websites, depending on the amount of the accommodation rate given by the hotel to the agencies or the online booking website. Previous studies have shown that many factors affect consumer attitude toward using social media in tourism, and more specifically with regard to hotel selection. The literature demonstrates the favorable marketing outcomes of social media on guests' attitudes and booking intentions in the hotel industry (Leung \& Baloglu, 2015) who proposed and tested an integrated model of Facebook hotel marketing. They suggested that compliance, internalization and identification are determinants of guests' attitudes toward a Facebook hotel page. Matikiti, Mpinganjira \& Roberts (2017) showed that attitude towards the use of SNS for trip organization is affected by the perceived benefits, with perceived usefulness having the greatest influence. Hua, Ramayah, Teoh \& Cheah (2017) modeled the use of social media as a tool to select tourism destinations. They found that perceived usefulness, perceived ease of use, perceived risk, and electronic word-of mouth (e-WOM) directly influenced attitude. In addition, the research shows that active participation on Facebook hotel pages enhances satisfaction by providing reliable information and expected benefits, consequently generating voluntary promotional behaviors and influencing consumers' information-searching and decision-making behaviors (Kang, 2018). Furthermore, Kim, Osman, Gyehee \& Hande (2018) studied the factors influencing attitude toward using social media with regard to festival attendance. They found that PE has a positive influence on ATUSM and that this is stronger among female users. On the other hand, PU has a stronger positive impact on ATUSM with regard to male users. In this study, attitude refers to an individual's positive evaluative effect in terms of using a given SNS.

\subsection{Perceived Usefulness (PU)}

Lin (2007) defined PU for social media sites as the confidence users have with regard to the features and capability of social media in terms of capturing the desired information, in such a way as to fulfill their requirements, generate the desired information for sharing and enrichment, while enhancing the users' decision making. In this study, PU reflects the benefits that customers will obtain from using SNS for hotel selection. Consumers prefer using social media marketing owing to the benefits they will obtain. Consumers can obtain various types of benefit (Hwang \& 
Cho, 2005; Chung \& Bulahis, 2008). These conist of functional, social, hedonic, psychological, and monetary benefits. Lopez, Bulchand-Gidumal, Tano \& Armas (2011) affirm that these benefits are not easy to establish because they change, based on the needs and nature of the consumer and their ability to use various types of social marketing. Furthermore, these authors recommend classifying these benefits into three main dimensions in the form of functional benefits, social benefits and hedonic benefits. In this study they pointed out that both functional and social benefits significantly influence attitude towards the usage of social media. Based on previous research results, this study will consider two types of benefit, functional benefits and social benefits. Other researchers such as Chung \& Buhalis (2008) and Sigala (2010) asserted that functional and social benefits have an important role to play in determining the use of social marketing. To ascertain this, the following hypothesis was formulated:

H1: Perceived usefulness will significantly influence the attitude towards the use of social networking sites in terms of hotel selection

\subsection{Perceived Ease of Use (PEU)}

Users' PEU refers to the degree to which they find a website easy to manage, are able to comprehend its composition and operate it with ease, and are able to obtain data and information when needed (Davis, 1993). In this study we are focusing on social media sites and hotel sites. It should be noted that ease of use comprises features such as structure and user-friendly interaction between the user and the service provider, and fulfilling the users' expectations and demands, especially in terms of information seeking (Leiva, Mendez \& Fernandez, 2012). Hsu \& Lin's (2008) study provided support for a positive relationship between PEU and attitude toward utilizing a blog. Nasri \& Charfeddine (2012) showed that PEU increased attitude toward utilizing Facebook. Accordingly, and based on these results, PEU is deemed to be a significant indicator of attitude (Cheung \& Vogel, 2013). To ascertain this, the following hypothesis was formulated:

H2: Perceived ease of use will significantly influence the attitude towards the use of social networking sites in terms of hotel selection

\subsection{Perceived Risk (PR)}

Perceived risk has been examined and defined across different field of studies. With regard to social media, risk can be defined as the possible threat or damage or insecurity associated with using social media services. Webber, Li \& Szymanski (2012) defined social media risk as the likelihood that a negative social media event will happen (multiplied by) the impact that the negative event will have if it does happen. Social media networks encourage people to provide personal information. Facebook, Twitter and YouTube allow for users to create a diverse personal user profile data concerning their interests and priorities, allowing them to represent themselves in the digital community. Disclosing their personal information to the public can translate into real risks. Details such as contact information, age, and other specific information can be misused or can result in identity theft (Han \& Maclaurin, 2002) or the hacking of personal information or passwords, which can then be used by criminals for fraudulent purposes (Immler, 2007). Site members may be subject to data theft and content alteration, and consequently may experience emotional discomfort, monetary loss, or reputation damage. According to Chena $\&$ Sharma (2013), private information divulged may be used against the user's will for purposes such as irritation, embarrassment, and extortion. Go, Chua, Lee \& Chua (2011) revealed that SNS adoption is influenced by perceived risk which creates an uncertain feeling pertaining to the negative outcomes associated with using SNS. It is more likely that risks associated with social media inversely affect the attitude of users towards social media usage. This study focuses on the risk factors that are applicable to social media use in terms of hotel selection. To ascertain this, the following hypothesis is formulated:

H3: Perceived Risk will significantly influence the attitude towards the use of social networking sites in terms of hotel selection

Drawing upon the relevant literature, a research model was developed as illustrated in Figure 1.

Figure 1: Research Model

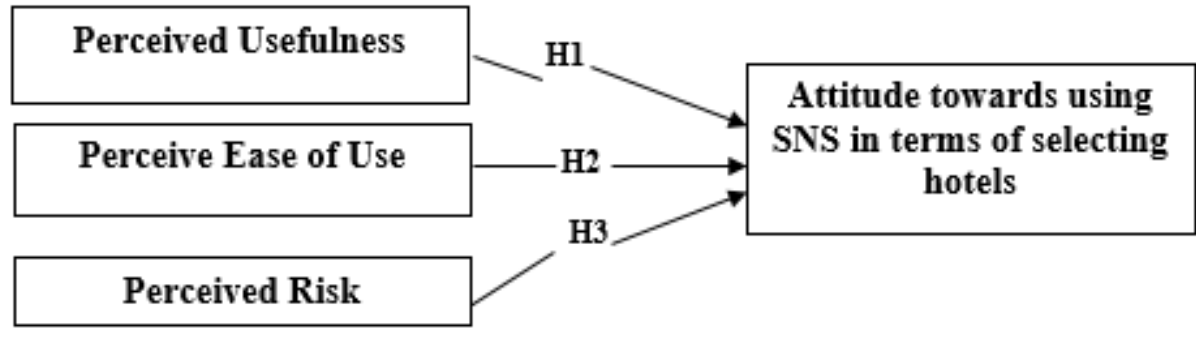

\section{Methodology}

This study uses an exploratory research design which employs quantitative data. This research examines the 
importance of different factors that are deemed to affect the attitude towards using social media for hotel selection in the UAE. A convenience sampling technique was used to distribute the paper-based, self-administered survey questionnaires on different hotels in the different emirates (Dubai, Sharjah, and Ajman). The target respondents were individuals who used social media sites as a method for hotel selection. In determining respondents who fulfilled the criteria set by the researcher, a question (i.e., whether the respondent used social media sites in selecting the hotel) was set as a filter at the beginning of the questionnaire About 350 questionnaires was distributed within the selected hotels, and many respondents agreed to participate and to return the completed questionnaire to the reception desk, while some respondents returned it directly to the researcher. In total, 313 questionnaires were returned. About 6 of these questionnaires were incomplete and were excluded from further analysis. Consequently, a total of 307 usable questionnaires were included in the data analysis.

\subsection{Measurement tool development}

The questionnaire consisted of two sections including study measures and demographic information. The four constructs of this study model as shown in Figure 1 were measured using validated measurement scales obtained from the extant literature. For ATUSM, questions were adopted from Hsu \& Lin (2008). In addition, items used to measure perceived usefulness and perceived ease of use were adopted from Lopez, Bulchand-Gidumal, Tano \& Armas (2011) and from Venkatesh \& Davis (2000), while in measuring perceived risk, questions were adopted from Mannuka \& Jarvi (2014). All items made use of a 5-point Likert-type scale, with anchors at 1 (strongly disagree) and 5 (strongly agree).

\subsection{Respondent profile}

Table 3 shows the demographic profile of the sample. There were more females (62.8 per cent) than males (37.1 per cent). The largest age group was 31-40 years old (49.5 per cent), followed by 41-50 years old (26.3 per cent) and finally by 20-30 years old with (24.1 per cent). About 32.2 percent of the respondents visit hotels 5-6 times per year, and 24.1 percent more than 6 times. Finally, 32.1 percent visit hotels 1-2 times per year. In terms of social media use, 31.5 per cent of the respondents used Facebook, 28 per cent used the hotel website for information, 25.4 per cent used Twitter, and finally 15 per cent used Trivago. Concerning type of work, employees from the private sector were most common at 37.1 per cent, those from the government sector made up 25.4 per cent, while visitors who own business made up 15.3 per cent, and students made up 11.7 percent. While Non-working were the lowest with 10.4 percent.

Table 3. Demographic Profile

\begin{tabular}{|l|c|c|c|}
\hline \multicolumn{2}{|c|}{} & Frequency & Percent \\
\hline Gender & Female & 193 & 62.8 \\
& Male & 114 & 37.1 \\
\hline Age group & $20-30$ & 74 & 24.1 \\
& $31-40$ & 152 & 49.5 \\
& $41-50$ & 81 & 26.3 \\
\hline Number of hotel & $1-2 /$ year & 71 & 23.1 \\
visits & $3-4 /$ year & 63 & 20.5 \\
& & 99 & 32.2 \\
& 5-6/yeare & 74 & 24.1 \\
\hline Social media & Facebook & 97 & 31.5 \\
used & hotel website & 86 & 28.0 \\
& Trivago & 46 & 15.0 \\
Type of & Twitter & 78 & 25.4 \\
work & Government sector & 78 & 25.4 \\
& Non-working & 32 & 10.4 \\
& Own business & 47 & 15.3 \\
& Private sector & 114 & 37.1 \\
\hline
\end{tabular}

\section{Results and Discussion}

A number of primary analyses were done in this preliminary stage - Corrected Item-Total Correlation (CITC), exploratory factor analysis and reliability evaluation by means of Cronbach alpha $(\alpha)$. According to Lu, Lai \& Cheng (2007), the aim of CITC analysis is to purify the constructs' measurement items by detecting insignificant items which may affect the interpretation of the factor analysis. CITC represents a correlation between an item (indicator) and the combined score of all the items measuring the same construct. CITC analysis was performed for each construct. Table 4 shows that all items obtained a CITC coefficient above the recommended edge value of 0.5 (Hair, Black, Babin \& Anderson, 2010). Cronbach alpha was calculated in order to ascertain scale reliability. 
This was greater than 0.7, meeting the standard cut-off value ((Hair, Black, Babin \& Anderson, 2010).). Exploratory factor analysis (EFA) was performed to detect the number of meaningful patterns factors that exist within the data. This is set by identifying items that do not belong to their theoretical constructs, or items that do not have a common core. In order to ensure that data are suitable in order to run factor analysis, the Kaiser-MeyerOklin (KOM) test of sampling adequacy and Bartlett's Test of Sphericity were performed. As indicated by Kaiser (1974), the minimum acceptable KOM value is 0.6, and Bartlett's Test of Sphericity should have a p-value of $<0.05$. In the case of the current study, the results show that KOM is 0.816 , while Bartlett's Test of Sphericity was inspected using the Chi-Square statistic which was 4732.170 and was significant at the $0 \%$ level $(\chi 2=3472.170$, $\mathrm{p}<0.000)$. These results show that the data is fit for conducting EFA. For the EFA, a principal factor analysis with Varimax rotation and eigenvalue greater than 1 and factor loadings greater than 0.5 , was performed. As can be seen in Table 4, the results of the EFA suggest that 4 factors were extracted with eigenvalues greater than 1 (F1: 7.226), (F2: 3.845), (F3: 1.999), and (F4: 1.225). As revealed in Table 4, all items loaded onto their underlying latent variables, and these loadings were significant. It was found that the average construct validity with significant loading values ranged from 0.568 to 0.928 , which is above the recommended loading value of 0.5 (Hair, Black, Babin \& Anderson, 2010). Overall, the 4 factors underlying the whole data accounted for $74.40 \%$ of the explained variance.

\subsection{Measurement model}

The results of the model fit indices of the measurement model were within the acceptable range. With regard to the reliability of the measurement scales, it can be observed from Table 5 that the factor loadings and the composite reliability of all the constructs were quite satisfactory. Therefore, all constructs had an adequate internal consistency. Furthermore, it can be seen in Table 5 that the average variance extracted (AVE) for each construct was well above the recommended value of 0.5 (Fornell \& Larcker, 1981).

Table4. Exploratory Factor Analysis Results

\begin{tabular}{|c|c|c|c|c|}
\hline Constructs & Mean & SD & $\begin{array}{c}\text { Factor } \\
\text { Loading }\end{array}$ & CITC \\
\hline $\begin{array}{l}\text { F1: Attitude Towards Using SM } \\
\text { 6. I believe that social media (Facebook, Instagram, Twitter..etc) is important for all } \\
\text { hotels } \\
\text { 7. I believe that social media can play an important role in booking hotel } \\
\text { accommodation. } \\
\text { 8. Using social media for booking hotel accommodation is not healthy for the } \\
\text { organization's reputation. }\end{array}$ & 4.8 & 0.44 & $\begin{array}{l}.629 \\
.716\end{array}$ & .631 \\
\hline $\begin{array}{l}\text { F2: Perceived ease of use } \\
\text { 9. Using social media for booking hotel accommodation will decrease work load. } \\
\text { 10. I believe that posting hotels on social media is cost saving } \\
\text { 12. I always use websites for looking for hotel accommodation. } \\
\text { 18. Online advertisements are a valuable source of information } \\
\text { 20. I believe that using social media is a good way to interact }\end{array}$ & 4.3 & 0.69 & $\begin{array}{l}.687 \\
.812 \\
.848 \\
.723 \\
.668\end{array}$ & $\begin{array}{l}.695 \\
.747 \\
.760 \\
.637 \\
.632\end{array}$ \\
\hline $\begin{array}{l}\text { F3: Perceived usefulness } \\
\text { 11. Social networking sites enable one to keep up to date with knowledge about hotels. } \\
\text { 13. Social networking sites allow one to reduce cost when searching for hotel } \\
\text { information } \\
\text { 14. Social networking sites offer the possibility of providing and receiving } \\
\text { information about hotels of interest } \\
\text { 15. Social networking sites allow one to stay in contact with friends who share the } \\
\text { same interests } \\
\text { 16. Social networking sites provide one with a strong feeling of belonging to a group } \\
\text { 17. I can provide direct feedback through e-WOM by using social media } \\
\text { 19. Through the use of social networking sites, one's personal relationships with } \\
\text { friends with similar interests increases }\end{array}$ & 4.8 & 0.41 & $\begin{array}{l}.568 \\
.811 \\
.829 \\
.808 \\
.824 \\
.719 \\
.843\end{array}$ & $\begin{array}{l}.635 \\
.823 \\
.858 \\
.799 \\
.759 \\
.705 \\
.825\end{array}$ \\
\hline $\begin{array}{l}\text { F4: Perceived Risk } \\
\text { 21. The use of social networking sites can cause one to lose control of the privacy of } \\
\text { one's personal information } \\
\text { 22. The use of social networking sites can result in one's personal information being } \\
\text { used without one's knowledge } \\
\text { 23. Internet hackers are likely to take control of one's account and use one's personal } \\
\text { information } \\
\text { 24. Use of social media sites results in loss of time } \\
\text { 25. Search for information on social media sites is time consuming }\end{array}$ & 4.7 & 0.51 & $\begin{array}{l}.895 \\
.924 \\
.904 \\
.928 \\
.806\end{array}$ & $\begin{array}{l}.834 \\
.874 \\
.828 \\
.822 \\
.717\end{array}$ \\
\hline
\end{tabular}


The square root of the AVE values shown on the diagonal in Table 6 are greater than the inter-construct correlations in their respective columns (Hair, Black, Babin \& Anderson, 2010). Hence, all the constructs had acceptable convergent and discriminant validity. The variance inflation factor (VIF) values from the regression analysis table were used for the estimation of multicollinearity between the study constructs. The results indicated that the VIF values for all the referred constructs ranged from 1.015 to 1.508 , which is far below the recommended cutoff value of 10 (Hair, Black, Babin \& Anderson, 2010). This indicated that the problem of multicollinearity did not exist in the dataset.

\subsection{Structural model}

The SEM output revealed that the research model fits the data well $\left(\mathrm{x}^{2}=269.568 ; \mathrm{df}=223 ; \mathrm{GFI}=0.924 ; \mathrm{AGFI}=\right.$ 0.901; CFI =0.941; RMSEA $=0.058 ; \mathrm{TLI}=0.95 ; \mathrm{NFI}=0.96$ ). The R2 value was 0.409 , which suggests that $40.9 \%$ of the variance in users' attitude may be explained by PU, PEOU, and PR. The findings revealed that Perceived Usefulness significantly influences consumer attitude towards the use of social marketing sites in terms of hotel selection $(\beta=0.214, \mathrm{p}<0.05)$. Perceived Ease of Use also has a significant influence on consumers' attitude towards the use of social marketing sites in terms of hotel selection $(\beta=0.488, p<0.05)$. The findings also reveal that Perceived Risk significantly influences consumers' attitude towards the use of social marketing sites in terms of hotel selection $(ß=0.119, \mathrm{p}<0.05)$. Thus, H01, H02 and H03 were all supported.

Table 5. Confirmatory Factor Analysis

\begin{tabular}{|c|c|c|c|}
\hline Constructs & $\begin{array}{c}\text { Standardized Factor } \\
\text { Loading }\end{array}$ & t-Value & Cronbach's $\alpha$ \\
\hline $\begin{array}{l}\text { F1: Attitude Towards Using SM (AVE } \\
=0.637 ; \mathrm{CR}=0.812) \\
\text { ATUSM3 } \\
\text { ATUSM2 } \\
\text { ATUSM3 }\end{array}$ & $\begin{array}{l}.790 \\
.712 \\
.787 \\
\end{array}$ & $\begin{array}{l}13.132 \\
10.210 \\
13.369 \\
\end{array}$ & 0.826 \\
\hline $\begin{array}{l}\text { F2: Perceived Ease of Use }(\mathrm{AVE}= \\
0.730 ; \mathrm{CR}=0.885) \\
\text { PEU1 } \\
\text { PEU2 } \\
\\
\\
\\
\\
\text { PEU3 } \\
\text { PEU4 } \\
\text { PEU }\end{array}$ & $\begin{array}{l}.867 \\
.844 \\
.897 \\
.746 \\
.716 \\
\end{array}$ & $\begin{array}{l}15.391 \\
15.020 \\
20.644 \\
13.564 \\
11.933\end{array}$ & 0.893 \\
\hline $\begin{array}{l}\text { F3: Perceived Usefulness }(\mathrm{AVE}=0.711 ; \\
\text { CR }=0.902) \\
\text { PU1 } \\
\text { PU2 } \\
\text { PU3 } \\
\text { PU4 } \\
\text { PU5 } \\
\text { PU6 } \\
\text { PU7 }\end{array}$ & $\begin{array}{l}.685 \\
.887 \\
.872 \\
.841 \\
.878 \\
.761 \\
.904\end{array}$ & $\begin{array}{r}8.574 \\
17.654 \\
16.657 \\
14.964 \\
17.993 \\
12.387 \\
21.581 \\
\end{array}$ & 0.911 \\
\hline $\begin{array}{l}\text { F4: Perceived Risk }(\mathrm{AVE}=0.689 ; \mathrm{CR}= \\
0.833) \\
\text { PR1 } \\
\text { PR2 } \\
\text { PR3 } \\
\text { PR4 } \\
\text { PR5 }\end{array}$ & $\begin{array}{l}.882 \\
.879 \\
.910 \\
.863 \\
.807\end{array}$ & $\begin{array}{l}17.853 \\
18.124 \\
22.256 \\
16.357 \\
14.114\end{array}$ & 0.905 \\
\hline
\end{tabular}

$\mathrm{AVE}=$ Average variance extracted; $\mathrm{CR}=$ Composite reliability 
Table6. Discriminant Validity Test

\begin{tabular}{|c|c|c|c|c|c|}
\hline Variables & ATL & $\mathrm{SM}$ & PEU & PU & PR \\
\hline $\begin{array}{l}\text { Attitude toward using social } \\
\text { media (ATUSM) }\end{array}$ & $0.637^{\mathrm{a}}$ & & & & \\
\hline Perceived Ease of Use (PEU) & $\begin{array}{r}0.492^{\mathrm{b}} \\
(0.241)^{\mathrm{c}} \\
\end{array}$ & 0.730 & & & \\
\hline Perceived Usefulness (PU) & $\begin{array}{c}0.598 \\
(0.394)\end{array}$ & $\begin{array}{c}0.580 \\
(0.338)\end{array}$ & 0.711 & & \\
\hline Perceived Risk (PR) & $\begin{array}{l}0.253 \\
(0.132)\end{array}$ & $\begin{array}{c}0.466 \\
(0.238)\end{array}$ & $\begin{array}{l}0.510 \\
(0.262)\end{array}$ & 0.689 & \\
\hline
\end{tabular}

Table 6 shows that the average variances extracted by latent constructs were greater than any squared correlations among constructs. This implies that the constructs were empirically distinct from each other (Bagozzi \& Yi, 1998). In summary, the measurement model's discriminant validity was deemed to be satisfactory. Figure 2: Hypotheses testing

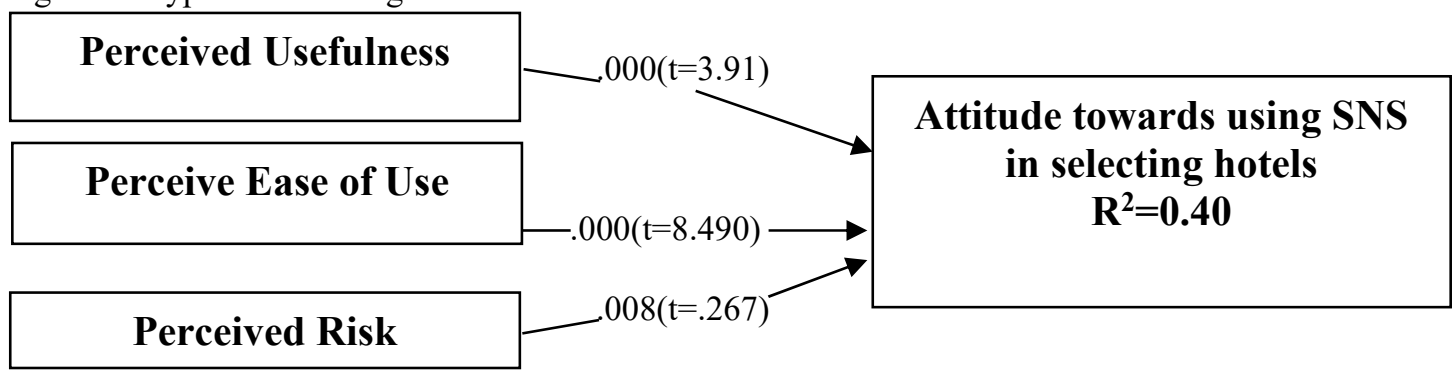

\section{Discussion and Conclusions}

The aim of this study is investigate the influence of different factors on consumers' attitude towards using social network sites in terms of the selection of hotels in the UAE. To achieve this goal, data were collected through a survey, and the model was tested by using SEM. The model showed a good fit with the data, and all the relationships hypothesized were supported. The factors include Perceived Ease of Use (PEU), Perceived Usefulness (PU), and Perceived Risk (PR). The findings revealed that PU $(\beta=0.214, p<0.05)$, PEU $(\beta=0.488$, $\mathrm{p}<0.05)$ and $\mathrm{PR}(\beta=0.119, \mathrm{p}<0.05)$ significantly influences consumers' attitude towards the use of social marketing sites in terms of hotel selection. We can conclude from this result that social network sites play an important role in terms of hotel selection in the UAE. These findings are new to the body of hotel social media research, and contribute to knowledge about the factors that influence consumers' attitude towards using social network sites in terms of the selection of hotels, largely because the study is among the first to examine those factors in the context of using social media with regard to hotel selection in the UAE. Most research tends to concentrate on the use of social media sites in the selection of tourism destinations (Hua, 2017), festival attendance (Kim, Osman, Gyehee \& Hande, 2018) and trip organization (Matikiti, 2017).

The proposed model in Figure 1 confirms that PEU is one of the key factors that influences consumers' attitude towards the use of SNS with regard to hotel selection. The findings concurred with those of Pietro, Virgilio \& Pantano (2012), in which the Ease of Use directly influenced the tourists' attitude toward the use of social networks in order to select tourism destinations. Pietro, Virgilio \& Pantano (2012) suggested that Ease of Use is strictly linked to attitude. Kim, Osman, Gyehee \& Hande (2018) found that PEU positively affects attitudes toward using social media. Hua, Ramayah, Teoh \& Cheah (2017) found that positive feedback with regard to Ease of Use is helpful in forming positive attitude on the part of tourists, and thus support the findings of the present study. The results confirm that PU is one of the key factors that influence an individual's attitude towards the use of SNS with regard to hotel selection. Two types of benefits were used in this study -functional and social benefits. This implies that functional and social benefits are important in building the PU construct. This indicates that consumers consider functional and social benefits as important motives for using SNS with regard to hotel selection. The finding corresponds with the findings of a previous studies conducted by Lopez, Bulchand-Gidumal, Tano \& Armas (2011), Sigala (2010) and Kim, Osman, Gyehee \& Hande (2018) and thus support the findings of the present study. To capitalize on this result, hotel strategies should focus on identifying the benefit that encourage consumer participation on Facebook hotel pages by providing valuable information. The results also show that the Perceived Risk (time and privacy risk) used in this study were significant. This implies that people are concerned about the privacy risk and time risk associated with the use of SNS. To maintain the success of a social networking site, it is important that users are keen to use the site to initiate social interactions and to boost the expansion of personal networks. On the other hand, networking services are perceived to pose significant threats to site members, 
and risks associated with site use are mounting. Evidence has underlined the potential risks of cyber security and privacy abuse in site use, and suggested that these risks may deter users from further engaging in site use (Kang \& Kim, 2006). By investigating the direct effects of PEU, PU and PR on ATUSM, this study add to current knowledge, and outlines several useful contributions for the improvement of hotel performance by focusing and using modern SNS and content type, as well as increasing security measures.

\section{Limitations of the research}

This study relied on convenience sampling, which makes it difficult to generalize the findings and account for changes that may occur in the attitude of consumers. Future studies could therefore use a random sampling technique and a longitudinal technique in this regard. One other limitation of this study is that it did not include the respondents' experience of using social media.

\section{References:}

Anderson Chris K. (2012). The Impact of Social Media on Lodging Performance. Cornell Hospitality Report, November, www.chr.cornell.edu

Brandwatch.com (2019). 122 Amazing Social Media Statistics and Facts. January 2019. https://www.brandwatch.com/blog/amazing-social-media-statistics-and-facts/.

Boyd danah M. \& Ellison Nicole B. (2008). Social Network Sites: Definition, History, and Scholarship. Journal of Computer-Mediated Communication 13 pp.210-230.

Bagozzi, R.P. \& Yi, Y. (1998). On the evaluation of structural equation models. Journal of Academy in Marketing Science. 16, 74-94.

Chena, Rui. \& Sharma S. K. (2013). Understanding Member Use of Social Net working Sites from a Risk Perspective. Procedia Technology 9, pp. 331-339, Science Direct.

Cheung, R., \& Vogel, D. (2013). Predicting user acceptance of collaborative technologies An extension of the technology acceptance model for e-learning. Computers and Education, 63, 160-175

Dann, S. \& Dann. S. (2011). E-Marketing: Theory and Application. Palgrave Macmillan London, U.K.

Davis, F.D. (1993). User acceptance of information technology: System characteristics, user perceptions and behavioral impacts. Int. J. Man-Mach. Stud. 38, 475-487.

Fotis. J., Buhalis. D. \& Rossides. N. (2012). Social Media Use and Impact during the Holiday Travel Planning Process. Retrieved from:http://eprints. Bournemouth .ac.uk/.

Fornell, C. \& Larcker, D.F. (1981) Evaluating structural equation models with un-observable variables and measurement error. Journal of Marketing Research, Vol. 18 No. 1, pp. 39-50.

Go, Y-H., Chua, BH., Lee, CY., \& Chua, E. NJ. (2011). The Effect of Risk Perception on the Usage of Social Network Sites: A Conceptual Model and Research Propositions. 2nd International Research Symposium in Service Management, Yogyakarta, Indonesia.

Garrido-Moreno, A. \& Lockett, N. (2016). Social Media Use in European Hotels: Benefits and Main Challenges. Tourism \& Management Studies, 12(1) 172-179. DOI: 10.18089/tms.2016.12118

Hansen, D. L., Shneiderman, B. \& Smith, M.A. (2011). Analyzing Social Media Networks with NodeXL: Insights from a Connected World. Burlington: Morgan Kaufmann.

Hsu, C. \& Lin, J.C. (2008). Acceptance of blog usage: The roles of technology acceptance, social influence and knowledge sharing motivation. Inf. Manag. 2008, 45, 65-74.

Han, P., \& Maclaurin, A. (2002). Do consumers really care about online privacy? Marketing Management, 11 (1), 35-38.

Hair, J. F., Black, W., Babin, B., \& Anderson, R. (2010). Multivariate data analysis $\left(7^{\text {th }}\right.$ ed.). Upper Saddle River, NJ: Prentice-Hall, Inc.

Hua Lim Yan, T. Ramayah, Teoh Ai Ping \& Cheah Jun-Hwa (2017). Social Media as a Tool to Help Select Tourism Destinations: The Case of Malaysia, Information Systems Management, 34:3, 265-279.

Immler, C. (2007). Das Notebook-Handbuch. Pearson Education. München, p. 425.

Jung Heejin, Gyehee Lee, Kyungsuk Hur, Taegoo Terry Kim (2018). Online travel information value and its influence on the continuance usage intention of social media. Serv Bus 12:85-120.

Kargwell, Samia (2016). Horizontal Revolution and Business Strategy: The Impact of Social Media Platforms on Departments' Business Strategy: The UAE context. Journal of Business \& Economic Policy Vol. 3, No. 1; March 58

Kaplan, Andeas M. \& Haenlein, Michael (2010). Users of the World, Unite! The Challenges and Opportunities of Social Media, Business Horizons 53, 59-68.

Kang, Y.S., \& Kim, Y.J., (2006). Do Visitors' Interest Level and Perceived Quantity of Web Page Content Matter in Shaping the Attitude toward a Web Site? Decision Support Systems 42 (2), p. 1187-1202.

Kang Juhee, (2018). Effective marketing outcomes of hotel Facebook pages: The role of active participation and satisfaction. Journal of Hospitality and Tourism Insights, Vol. 1 Issue: 2, pp.106-120, 
Kim, W. \& Park, S. (2017). Social media review rating versus traditional customer satisfaction: which one has more incremental predictive power in explaining hotel performance? International Journal of Contemporary Hospitality Management, Vol. 29 No. 2, pp. 784-802.

Kim Woo-Hyuk, \& Chae Bongsug, (2018). Understanding the relationship among resources, social media use and hotel performance: The case of Twitter use by hotels. International Journal of Contemporary Hospitality Management, Vol. 30 Issue: 9, pp.2888-2907.

Kim Taegoo T., Osman M. K., Gyehee Lee, \& Hande Demiral (2018). Do Gender and Prior Experience Moderate the Factors Influencing Attitude toward Using Social Media for Festival Attendance? Sustainability, 10, pp.119.

Kaiser F. (1974). An index of factorial simplicity, Psyhometrika, vol. 39, no. 1, pp. 31- 36.

Lopez, E.P., Bulchand-Gidumal, J., Tano, D.G. \& Armas, R.J.D., (2011). Intentions to use social media in organizing and taking vacation trips, Computers in Human Behavior 27(2), 640-654. http://dx.doi.org/10.1016/j.chb.2010.05.022

Lin, H. F. (2007). The role of online and offline features in sustaining virtual communities: An empirical study. Internet Research, 17(2), 119-138.

Leung Xi Y., Billy Bai, Mehmet Erdem (2017). Hotel social media marketing: a study on message strategy and its effectiveness. Journal of Hospitality and Tourism Technology, Vol. 8 Issue: 2, pp.239-255.

Luo, Q. \& Zhong, D. (2015). Using social network analysis to explain communication characteristics of travelrelated electronic word-of-mouth on social networking sites. Tourism Management, Vol. 46, pp. 274-282.

Leiva, F. M., Mendez, J. H., \& Fernandez, J. S. (2012). Generalizing user behavior in online travel sites through the Travel 2.0 website acceptance model. Online Information Review, 36(6), 879-902.

Lu C., K. Lai \& T. Cheng (2007). Application of structural equation modeling to evaluate the intention of shippers to use internet services liner shipping, European Journal of Operational Research. vol. 180, no. 2, pp. 845867.

Leung Xi Yu, \& Baloglu Seyhmus, (2015). Hotel Facebook marketing: an integrated model", Worldwide Hospitality and Tourism Themes, Vol. 7 Issue: 3, pp.266-282.

Munar, A.M. \& Jacobsen, J.K.S. (2014). Motivations for sharing tourism experiences through social media. Tourism Management, 43, 46-54.

Madni G. Rasool (2014). Consumer's Behavior and Effectiveness of Social Media. Global Journal of Management and Business Research: E Marketing. Vol. 14 Issue 8 Version 1.0

Matikiti, R., Mpinganjira, M. Roberts-Lombard, M., (2017). Social media in tourism: Establishing factors influencing attitudes towards the usage of social networking sites for trip organization. Acta Commercii 17(1), a396. https://doi. org/10.4102/ac.v17i1.396.

Nasri,W. \& Charfeddine, L. (2012). An exploration of Facebook.Com adoption in Tunisia using technology acceptance model (TAM) and theory of reasoned action (TRA). Int. J. Contemp. Res. Bus. 4, 948-968.

Pietro, D. L., Virgilio, D. F., \& Pantano, E. (2012). Social network for the choice of tourist destination: Attitude and behavioral intention. Journal of Hospitality and Tourism, 3 (1), 60-76.

Quach, Jimmy (2017). Social Media Marketing in the Hotel Industry: Trends and Opportunities in 2017. HVS.

Riley, J.A. (2010). 2011 Social Media Directory: The Ultimate Guide to Facebooks, Twitters and LinkedIns Resources, Que Publishing, Indianapolis, IN.

Sigala, M., Gretzel, U. \& Christou, E. (2012). Social Media In Travel, Tourism And Hospitality: Theory, Practice And Cases, VT: Ashgate, Farnham, Surrey, Burlington

Statista (2017). Number of monthly active Facebook users worldwide as of 2nd quarter 2017 (in millions). available at: www.statista.com/statistics/264810/number-of- monthly-activefacebook-users-worldwide/ (accessed October 1, 2018).

Shen Han, Chengyi Song, Mimi Li, Qian Jiang, (2015). Shaping Destination Images through Social Networking Sites: A Case Study of Singapore. In Advances in Hospitality and Leisure. 12 Nov; 89-107.

Trusov, M., Bucklin, R. \& Pauwels, K. (2009). Effects of WOM versus traditional marketing. Findings from an internet social networking site, Journal of marketing, Vol.73 No.5, pp.90-102.

Varkaris, E. \& Neuhofer, B. (2017). The influence of social media on the consumers' hotel decision journey, Journal of Hospitality and Tourism Technology, Vol. 8 Issue:1, pp.101-118, https://doi.org/10.1108/JHTT09-2016-0058

Venkatesh, V. \& Davis, F.D. (2000). Theoretical extension of the technology acceptance model: Four longitudinal field studies. Management Sci., 46, 186-204.

UAE Social Media Usage Statistics (2018). Posted in Info graphics, Social Media Marketing May 4th, 2018.

Webber, A., Li, C., \& Szymanski, J. (2012). Guarding the Social Gates: The Imperative for Social Media Risk Management: Altimeter Group, August 9, 2012. 